\title{
THE CHALLENGE OF SMART MOBILITY INTEGRATION IN THE EVOLVING SMART CITY CONTEXT; THE PARADIGM OF HERAKLION
}

\author{
Efthimios Bakogiannis, Maria Siti, Stefanos Tsigdinos, Georgia Christodoulopoulou \\ and Christos Karolemeas \\ National Technical University of Athens, Heroon Polytechneiou 9, Zographos 15780, Greece
}

\begin{abstract}
Contemporary cities face significant challenges, particularly due to climate change and the rapid urbanization. Therefore, a new concept has emerged, utilizing the striking technological progress. This paradigm is no other than the Smart City; a city that responds to the needs of its residents for managing assets and resources in a sustainable and efficient way through the use of information and communication technologies (ICTs). The smart cities' concept has six main areas: Government, Mobility, Environment, Economy, Living and People. Urban Mobility, although remaining one of the toughest challenges, is not always adequately integrated in Smart Cities' schemes particularly in Greece, where it is often undermined or completely forgotten. In this context, the paper aims at highlighting the importance of smart mobility as a fundamental element of Smart Cities. Moreover, it proposes a Smart Mobility Strategy along with its evaluation process for the city of Heraklion in Greece, which can be used as guide for other cities in the field. The research presents nine (9) grouped sets of policy interventions and measures as well as five (5) categories of evaluation indicators to be applied in cities with similar characteristics. The proposed actions and indicators can be integrated in the planning procedure towards smarter, more sustainable and more efficient cities.
\end{abstract}

\section{KEYWORDS}

Smart Cities, Smart Mobility, Policy Actions, Assessment Indicators, ICT Tools, Heraklion City, Greece

\section{INTRODUCTION}

Urban areas have been facing extremely serious challenges in recent years, especially due to the crucial consequences of climate change and the rapid process of urbanization (Papa et al., 2017; Caragliu et al. 2009). Environmental deterioration, traffic congestion, poverty, inadequate housing conditions, inequalities, accessibility deficiencies, constitute some of the serious issues that contemporary cities face (Jabareen, 2006, Dameri, 2017). This situation demands an effective and resilient planning and development perspective (Pickett et al., 2004). Therefore cities must now embark on a process of transformation by developing strategies to counter the negative impacts of urbanization and bring prosperity to the urban environment (Aleta et al., 2017). A new city development model that has emerged from the late 1990's (Neirotti et al., 2014) utilizing the notable technological process, is called the "Smart City" (Garau et al., 2016). According to Caragliu et al. (2009), a city is smart when 'investments in human and social capital and traditional (transport) and modern (ICT) communication infrastructure fuel sustainable economic growth and a high quality of life, with a wise management of natural resources, through participatory governance'. A smart city is defined by its efficiency and livability as well as by its use of innovative operational and information technology. One of the key issues determining the new era of cities, is the ability of gathering, using and leveraging a meaningful amount of data (stored or real-time) in order to improve services directed to their citizens, decrease costs in energy consumption etc. A Smart City should perform sufficiently in six (6) key fields of urban development, built on the 'smart' combination of endowments and activities of self-decisive, independent and aware citizens (Giffinger et al., 2007). These fields are smart economy, smart governance, smart living, smart people, smart environment and smart mobility (Caragliu et al., 2009). 
Cities tend to compete regarding their positioning in the global rankings in order to alter or enhance their future development, identify strengths and weaknesses as well as take advantage of the existing good practices and transfer knowledge and practices. Research in smart cities has well adopted this competitive approach, while monitoring data in transportation terms became the norm for Sustainable Urban Mobility Plans and hence Smart Mobility'. There are plenty of ranking systems, such as the Smart City ranking by Boyd Cohen, the European Smart Cities, the Juniper's Smart City Rankings, the Deloitte City Mobility Index, the Intelligent Community Forum assessment as well as panels from global and European stakeholders (i.e. the World Bank, universities, UN Habitat representatives etc.), listing cities that perform well in one or more of the afore-mentioned sectors. These rankings can directly assist cities in global and regional recognition as they draw public attention as well as attract several investment and development funding. More and more projects are being implemented within the concept of smart cities with the formulation of partnerships and other entities participating in programs such as INTERREG, URBACT, HORIZON 2020, CIVITAS etc.

One the most significant pillars of Smart Cities is Smart Mobility (Vanolo, 2014) which refers to the transportation sector of an urban area (peoples or goods) aiming to go one step further by searching for innovative and sustainable ways to provide mobility for people in cities -by developing environmentally-friendly public transport fuels and propulsion systems supported by technology, and the proactive behavior of citizens (Neirotti et al., 2014). However, this particular field is not always adequately integrated in Smart Cities' schemes. Especially in Greece, Smart Mobility is often undermined or completely forgotten (Bakogiannis et al., 2017), and that undoubtedly constitutes a serious hindrance in the way towards the making of sustainable, just and functional cities.

The aim of this research is primarily to highlight the importance of smart mobility as a fundamental element of Smart Cities and propose a Smart Mobility Strategy along with its evaluation process for a specific case study. The case study of this research is the city of Heraklion in the island of Crete. Heraklion is the $4^{\text {th }}$ largest urban formation in Greece, having approximately 175.000 residents and the past few years has carried out notable efforts in the Smart City case, recognized by the New York- based Intelligent Community Forum on the list of 21 smart cities in the world for the years 2012, 2013 and 2014. However, Heraklion remains insufficient on implementation of smart mobility policies and actions ranking, low on all relevant indicators.

\section{SMART MOBILITY: DEFINITIONS AND PERSPECTIVES}

Conventional urban and transport planning have dealt so far with practices that tend to meet demands by improving capacity through car-oriented approaches especially in cities where urbanization is rapidly growing. Typical solutions have led to car-favoring development patterns (Marshall, 2005), which also drive the land use patterns in unsustainable city forms. Numerous researchers and studies consider transport to be among the three most energy consuming activities, with the other two being the sectors of housing and food production (Schafer et al., 2009). Therefore, a complete shift to a sustainable and efficient transport system is urgent. Sustainable urban mobility is considered as an emerging field in transportation and environmental studies-particularly in the European transport Agenda- introducing policies and practices to face problems such as traffic congestion, air and noise pollution, road safety etc. The need for sustainable urban mobility has been distinctly described only after 2001 (CEC, 2001), with the Green Paper from the European Commission being finalized and issued in mid- 2007 entitled 'Green Paper- Towards a new culture for urban mobility' (CEC, 2007). Later on, in 2011 the European Commission, via the White Paper 'Roadmap to a Single European Transport Area - Towards a competitive and resource efficient transport system', adopted a roadmap of 40 concrete initiatives for the next decade to build a competitive transport system that will increase mobility, remove major barriers in key areas and fuel growth and employment (CEC, 2011). Recently, the introduction of Sustainable Urban Mobility Plans (SUMPs) contributed significantly to the enhancement and promotion of sustainable mobility in urban areas. Even medium or small sized cities have now the possibility of recreating their urban environment towards efficiency, vitality and sustainability. A Sustainable Urban Mobility Plan is "a strategic plan designed to satisfy the mobility needs of people and businesses in cities and their surroundings for a better quality of life. It builds on existing planning practices and takes due consideration of integration, participation, and evaluation principles" (Wefering et al., 2014). 
One of the key elements of sustainable mobility, which is also embedded in SUMPs, is the concept of Smart mobility. According to Vanolo (2014), smart mobility constitutes one of the main urban strategies to pursue city sustainability. Smart mobility uses ICT not only to collect, process and spread information about the traffic in city, but also to implement Intelligent Transport Systems (Dameri, 2017) and to promote sustainable means of transport (e.g. bicycles, eco-vehicles, car sharing) that respect the environment. The novelty is thus not so much the individual technologies, products or services but the interconnection and the synchronization of these and the systems they include, so that they can function in concerted action (Hojer and Wangel, 2015). Nevertheless, smart mobility is not solely a technological affair, but also a social and cultural approach (Benevolo et al., 2016). Furthermore, it should be noted that a smart mobility system requires a variety of infrastructure types, including physical infrastructure, operational and information technologies. Without any single component of this system, smart mobility products cannot meet their full potential to achieve operational efficiency and manage the users' demand (Schneider Electric, 2014). Dameri (2017) states that smart mobility is one of the most promising topics, as it could produce high benefits for the quality of life of almost all the city stakeholders. Through literature review, it is possible to gather the most significant smart mobility objectives (Ambrosino et al., 2015; Lawrence et al., 2006; Bencardino and Greco, 2014) which are summarized in the following six categories: 1 . reducing pollution; 2 . reducing traffic congestion; 3 . increasing people safety; 4. reducing noise pollution; 5. improving transfer speed; 6 . reducing transfer costs. Smart solutions in mobility terms consist of systems, applications, implementation of policies, designs and plans, indicator's assessment and many more. Some solutions can only be adopted by cities that have already implemented progressive transport planning including walking, cycling and public transport infrastructures parameters; while other solutions can support cities that are at a critical point in terms of tech industry revolution. Anyhow, smart mobility services are changing the way cities move, while at the same time "smart infrastructure" projects are becoming commonplace. More and more cities are implementing practices and policies related to intelligent transport systems (ITS) and many of them are investing in infrastructure that can assist in the transition to an up-to-dated 21 st century urban mobility agenda. This agenda should place innovation at its core (CEC, 2011), thus including different technology- assisted services, alternative use of vehicles, introduction of the 'sharing' culture, innovative integration of traditional traffic calming tools, implementation of customized solutions and a communicative participatory approach for information and awareness raising.

Greek cities being formally obliged to follow European strategies have implemented several, however abstract, practices related to transportation and smart mobility. European Funds (Horizon 2020, Interreg etc.) have allowed the development of a number of strategies, projects, mobility practices and services related to the smart city concept in cities such as Athens, Piraeus, Thessaloniki, Thermi, Trikala, Heraklion and others. Innovations in smart mobility are more profound in Thessaloniki (project Intelligent Thessaloniki) as well as in the city of Trikala (project CityMobil2), where the first autonomous bus has completed its pilot application and tested in real traffic conditions, while also Piraeus (project CYCLECITIES, SMILE, MOBILITAS) has participated in a number of innovative mobility projects. Although several projects regarding mobility have been implemented, development has mostly focused on pilot services and the output data are not integrated in the future strategic municipal or regional planning. Similarly, the tools and innovative services developed by these projects do not seem to be upgraded in following schemes or applied in future technologies. Furthermore, public- private partnerships in Greece do not follow the European norms, and thus it is difficult to promote the concept of sustainable competitiveness as a driver of prosperity and long-term growth in terms of sustainable mobility. Initiatives are driven either by public entities (universities and research centers) or by businesses and project consultants whose interest is usually limited to the end of each program (Bakogiannis et al., 2017).

\section{HERAKLION PARADIGM; INTEGRATING MOBILITY IN THE MUNICIPAL SMART CITY STRATEGY}

Heraklion is a dynamic Mediterranean city of Greece and the largest city of the island of Crete. Urban development has been defined by sprawl, incohesive planning and car-dependency, however the public transport system has been improved in terms of services and operation management. Although there are numerous fruitful discussions and attempts which embrace sustainable urban mobility and promote smart mobility in the planning discourse, it is profound that there is still a long way to go in order to achieve an efficient level of human-centered mobility. The particularities in the urban environment, such as the narrowness 
of the street form, the lack of organized on and off street parking spaces, the short distances and the sense of enclosure in existed inner-city neighborhoods, provide an ideal environment for combined smart mobility tools. Policy directions as well as actions should involve a range of traditional and innovative research tools that would put an emphasis on participatory processes which can raise awareness and somehow motivate citizens' engagement.

\subsection{Specification of Heraklion's Smart Mobility Strategy}

Heraklion aims to be transformed into a sustainable, accessible and truly smart city in mobility terms. It will be a city not based solely on the automobile, but a place that promotes walking, cycling, collective and shared transportation through a functional network with well aware and informed commuters. The Strategy on Smart Urban Mobility consists of 9 sub-sections (according to SUMP principles): a) Walking, b) Bicycle, c) Collective Transportation, d) Traffic Management and Private Vehicle Circulation, e) Speed Management and Road Safety, f) Innovative Means of Transport \& Shared City Concept, g) Clean Vehicles, Logistics \& Supply Management and h) Education-Communication-Awareness. Each one of the aforementioned sections includes innovative and core actions, which are described briefly below, mentioning also issues about their social acceptance, the expense and funding possibility balance as well as their contribution to sustainable mobility.

Walking is the most free and independent way of travelling around the city. The programmed innovative actions include; a) pilot testing and installation of special ICT urban equipment (signs, benches, lighting, shelters, stops, information and/ or sale kiosks etc.), b) development of systems to measure pedestrian flows and identify the geography and patterns of most used routes, c) installation of smart and accessible bus stops and Taxi stops, d) electronic accessibility rehabilitation of the transport system for disabled people as well as other vulnerable users (i.e. ticket issuing) and e) upgrade of the existing municipal APP or new Application development for crowdsourcing data collection while walking in the city (incl. existing functions such as problem reporting, points of interest etc.). The core actions regarding Walking include; a) improvement of sidewalks and pedestrian crossings in the context of the contemporary legislation and the urban mobility principles, b) improvement of street junctions facing inadequate road safety features, particularly on areas around school complexes and areas with increased pedestrian flows, c) development of traffic calmed roads and traffic calming areas (e.g. in central and suburban neighborhoods d) development of Pilot Urban Mobility Neighborhoods (one per municipal unit), e) upgrade of the existing green routes and development of an Eco-Cultural Network along significant routes, f) special provisions for each different disability category (e.g. different requirements for blind people, people with reduced mobility etc.) and g) improvement of accessibility in Public Transport Stops and taxi stops and enhancement of multimodality between pedestrian-PT system, cyclists' -PT system, pedestrian-cyclist, private vehicle-PT, private vehicle-cyclist etc. (e.g. on the main city gates, crucial junctions etc.). The social acceptance of the aforementioned actions is medium to high due to several completed interventions, while the innovation and the smartness of the measures can attract many funding resources, thus minimizing cost issues. The contribution to sustainable mobility is great, as they enhance the smart dimension of mobility in Heraklion. The presence of the FORTH institute in the vicinity allows for several pilot testing and attraction of relevant funds. The first three innovative actions $(a, b, c)$ are already funded, while the fifth action (e) is already in the development phase with ensured funds and high social consensus. Most of the core actions are programmed to be implemented through the SUMP funding, which is mostly confirmed by the municipal budget.

Cycling has similar benefits to walking, but can be easily used for long-distance travels. The innovative actions include; a) upgrading of the existing bike sharing system for citizens (residents and visitors) with a 24/7 dock less system and electronic application support, b) installation of an electronic system for dispensing shared bikes to citizens (residents and visitors) with 24/7 lending system and electronic application support either from specific delivery and receipt points (dockless with designated parking lot) either completely dockless, c) research on the utilization of electric scooters and segways as last mile alternative commuting modes, d) use of environmentally friendly electric bicycles (in passenger and freight transport), e) development of a smart bike flow measurement system to identify the geography of the most frequently selected routes, and f) development of an application with various data (or enhancement of existing apps) aiming at a readable and complete navigation system for cyclists. The core actions regarding Cycling include; a) development of a complete cycling network (cycle lanes, cycle corridors and mixed use streets) as well as bicycle parking 
stations, b) improvement of crossings with emphasis on the safe passage of pedestrians and cyclists c) promotion of public spaces and network integration for pedestrians and cyclists and d) improvement of accessibility in Public Transport Stops and taxi stops and enhancement of multimodality between pedestrian-PT system, cyclists-PT system, pedestrian-cyclist, private vehicle-PT, private vehicle-cyclist etc. (e.g. on the main city gates, crucial junctions etc.). Regarding the social acceptance of the above actions in terms of cycling, those that do not claim streetspace from the motor vehicles (i.e. core action a) have been already welcomed along with those promoting road safety (i.e. core actions b \& c). The public-private cooperation in the field of bike sharing (incl. innovative actions a, b, c, e) allows for the feasibility of most actions to be high, while the cooperation of the municipality with renowned research institutes and local universities is already promoting innovative actions e and f. Lastly the recent public engagement meetings with public transport operators and taxi union's representatives show their eagerness to support multimodality (core action d) however only if financial incentives are provided for any conversions.

Public Transport should be the backbone of the city's transport infrastructure. The benefits to residents and visitors vary, with the most important being road safety, sociability and economic efficiency. The innovative actions include; a) research on the feasibility of developing a Light Rail Transit Network, b) utilization of clean electric buses and smaller vehicles with emphasis on routes serving the most congested areas (for example city center, University, Airport, Archeological site of Knossos, etc.), c) improvement of the installation of telematics system for passengers' information and interfacing through "DIMOTIS" application for remote information, d) construction of (electronic) accessible infrastructure for people with disabilities and vulnerable citizens' groups, e) research on the potential integration of a single electronic ticket for bus and taxi (and bus-tram in the future), f) development of efficient public transport management technologies, g) sensor installation on Public transport vehicles in order to enhance traffic and pollution monitoring in the urban area of Heraklion and h) installation of smart bus stops. The core actions regarding Public Transport include; a) reorganization of existing routes and development of new Public Transport connections, b) installation of new accessible stops and stations, upgrading of existing stops and reallocation of the Taxi stations in order to serve complementary to public transport network, c) enhancement of multimodality for better service of the system pedestrian-public transport, cyclist-public transport (bicycle dragging), taxi-pedestrian, taxi-public transport, taxi-cyclist, etc.), d) provision of exclusive road space for public transport (e.g. bus lanes in arterial roads) e) development of Park \& Ride Infrastructure at the outskirts of the city and f) route enhancement, necessary route changes and development of a strategy to tackle seasonal variation of demand due to tourism activities through smart integration of Taxi and Public Transport. The aforementioned measures are characterized by medium to high social acceptance, although some of them are considered difficult to be accepted by the locals (e.g. innovative action a, core action d; Provision of exclusive road space for public transport) and they also present a medium to high level of cost- benefit equilibrium. The key weaknesses identified in the field that reduce the feasibility of several actions include the severe underfunding in public transportation that complicates innovative actions a and $\mathrm{h}$ as well as core actions e and $\mathrm{f}$.

Private car is not only the leading factor in creating traffic congestion in cities, triggering traffic incidents, but also one of the most important causes of air pollution, Greenhouse effect and, in general, urban degradation. The motorcycle also operates towards the same direction; however it occupies significantly less space. It is therefore urgent to severely limit their dominance and improve their circulation in certain sectors. The innovative actions regarding Traffic Management and Private Vehicles Circulation include; a) establishment of Traffic Control Center (including connected vehicles management), b) development of a system for traffic data collection and provision of real-time navigation information, c) variable message system (VMS) installation, d) development of a smart system for controlling short-term parking and variable parking spaces in the city center and the densely populated suburbs or neighborhoods of the city, e) development of a smart system for preventing illegal parking at predetermined points (i.e. pedestrian crossings), f) development of a navigation and parking assistant application for mobile phones aiming at the prevention of unnecessary parking searching, g) improvement of traffic management with smart signaling and h) import of electric vehicles and their charging points at central places of the city. The core actions regarding Traffic Management and Private Vehicles Circulation include; a) road network classification and relevant policies, b) development of traffic calmed areas in combination with prevention of through traffic in neighborhoods, c) permanent or Temporary Interventions in order to prevent illegal parking, d) improvement of mobility conditions around school complexes by creating mobility plans to promote alternative modes of transport -school mobility plans (e.g. walking/ cycling bus, carpooling), e) improvement of mobility in organizations through the creation of mobility plans- work travel plans (e.g. Commuters to the University 
Hospital of Heraklion, University, Companies located in the Industrial Area etc.) and f) development of Park \& Ride Infrastructure at the outskirts of the city. The social acceptance of the above actions is high, the smartness of the measures has already attracted several funding resources - although few of them confirmed, thus tackling the large cost of particular measures (e.g. establishment of a traffic control center) and the contribution to sustainable mobility is great, as they enhance efficiency of the whole transport system.

Speed is one of the most important operating factors of an area's road network. High speed road networks are creating conditions of increased risk, resulting in more traffic accidents. The innovative actions referring to Speed Management and Road Safety include; a) development of a system for traffic data collection and provision of real-time navigation information, b) combination of ICT tools for monitoring of environmental and traffic issues, c) implementation of innovative ways for traffic monitoring and road maintenance (identification and improvement of dangerous points and systematic monitoring of driving behavior) and d) variable message system (VMS) installation in order to inform and warn drivers for speed limits, real-time network situation, etc. The core actions are; a) reduction of speed limits across the city at $40 \mathrm{~km} / \mathrm{h}$ and in the neighborhoods from 20 to $30 \mathrm{~km} / \mathrm{h}$ (in combination with case specific traffic calming interventions at crucial sites such as schools), b) traffic calming measures for enhancing vulnerable users' accessibility, c) redesign of junctions for road safety in key spots and d) redesign of traffic signs in conjunction with restrictions for through- traffic. The public perception of such measures is positive however lacks the extensive funding to cover the overall actions. The feasibility of several actions is high (innovative actions a, $\mathrm{c}, \mathrm{d}$ and core actions $\mathrm{a}, \mathrm{b}, \mathrm{c}$ and d) due to completed traffic studies which are time-consuming and set the precondition for funding. The need to create sustainable, social and functional cities requires a shift to innovative modes of transport, which will be shared and allow public and collective use. The innovative actions regarding Innovative Means of Transport \& the Shared City Concept include; upgrading of the existing bike sharing system for citizens (residents and visitors) with a 24/7 dockless system and electronic application support, b) installation of a new electronic system for dispensing 200 more shared e-bikes to citizens (residents and visitors) with automatic lending and support from an electronic application either from specific delivery and receipt points, either completely dockless, c) research on the utilization of electric scooters and segways (dockless or not) as an alternative last-mile commuting mode, d) integration of mini/ midi buses into the Public Transport System for developing on-demand services, e) research on the introduction of financial or other incentives for the enhancement of collective and shared modes of transport and f) support of private initiatives regarding car sharing. The high social acceptance of all the above measures due to the national trends in the sharing economy and the presence of private investors allows for the increased feasibility of the actions.

Emissions from conventional motor vehicles are considered the most serious drivers of greenhouse gas emissions, pollution etc., while the noise they produce generates significant nuisances in the urban environment and quality of life. Therefore, the shift to new clean vehicles is considered imperative and Heraklion aims to be at the forefront of such transformation. The innovative actions regarding Clean Vehicles include; a) promotion of gradual replacement of municipal vehicles' fleet (e.g. garbage truck, school buses etc.) with clean vehicles, b) promotion of gradual replacement of public transport vehicles' fleet with clean vehicles, c) installation of a functional e-mobility charging network, and d) research on the introduction of financial or other incentives for the integration of E-mobility in organizations \& companies with large vehicle fleets. The aforementioned actions are expected to be welcomed by the local society as information and awareness for clean vehicles will be established in the area. National funding along with economic incentives can ensure the implementation of most actions while the participation of the private sector is expected to cover the various operational costs.

Logistics and Supply management is now seen as a key sector of any urban mobility strategy. Innovative actions proposed are; a) support of gradual implementation of cooperative transport systems in freight transportation, b) promotion of gradual replacement of the conventional supply vehicles (trucks and motorcycles) with green and shared vehicles, and c) combined management of supply chain activities and parking policies. Furthermore, the core action suggested is the development of Sustainable Urban Logistics Plan (SULP) in order to adopt a holistic and efficient approach of the issue. The feasibility of such actions depends highly on the reactions and adaptability of logistics' companies as well as on national policies. Although the social acceptance of such actions is positive, the feasibility of the actions is inextricably related to the maturity of the supply chain operators.

Substantial change in urban transportation and mobility behavior will not be managed if there is no change in the citizens' attitude and everyday choices. The innovative actions regarding Education-Communication-Awareness Raising are; a) the development of awareness raising campaigns for 
the role of technology in urban transportation and mobility and b) conducting of workshops aiming at familiarizing travelers in participatory planning and the use of crowdsourcing applications. The core actions are; a) information and awareness raising actions and campaigns on issues of transportation, urban mobility, accessibility and parking, and b) combined informative actions for children and the elderly (emphasis on target groups: children, elderly people, people with disabilities, etc.) on issues of mobility choices and road safety. Such actions are in place for Heraklion, which was awarded as the best big city in Greece for awareness raising activities during the European Mobility Week 2018, while future actions have ensured funding and are going to be completed with the participation of volunteers and various stakeholders.

The feasibility of measures (social consensus, cost-fund efficiency, contribution) has been examined thoroughly, but is not presented at this particular point due to the limited extent of the paper.

\subsection{Monitoring of Smart Mobility. Challenges and Perspectives}

A key element for the municipality's involvement in international city networks, partnerships in European and international programs, as well as an important parameter in the municipality's rating in official cities' ranking, that affect cities' funding and financial support, is the assessment and evaluation of the proposed actions through a proper set of indicators (Aleta et al., 2017). The selected indicators, which quantify attributes related to sustainable urban mobility, are used as benchmarking tools to monitor sustainable mobility in different urban areas (Pitsiava- Latinopoulou, 2012). The indicators selected in this particular study for Heraklion are 41 and they are related to the various objectives of the proposed strategy. Furthermore, they were classified into the following categories; Outcome indicators (15), transport activity indicators (11), output indicators (5), input indicators (3) and contextual indicators (7). It should be noted that this study not only suggests the appropriate evaluation indicators, but also forms a coherent table which includes the definition of the indicators, the implementation area, the data collection methods, the competent bodies as well as the financial resources. This holistic approach ensures the efficiency and the functionality of the suggested evaluation method and can contribute considerably in the improvement of the proposed strategy. A sample of this overall table is presented below.

Table 1. Sample of Indicators' Table

\begin{tabular}{|c|c|c|c|c|c|c|}
\hline Indicator & Category & Definition & $\begin{array}{l}\text { Application } \\
\text { area }\end{array}$ & Data Collection & Competent bodies & $\begin{array}{l}\text { Financial } \\
\text { resources }\end{array}$ \\
\hline $\begin{array}{l}\text { Killed and seriousl } \\
\text { injured by mode }\end{array}$ & $\begin{array}{l}\text { Outcome } \\
\text { Core } \\
\underline{\text { Safety }}\end{array}$ & $\begin{array}{l}\text { Number of people killed or } \\
\text { seriously injured in traffic } \\
\text { accidents }\end{array}$ & $\begin{array}{l}\text { City wide or on } \\
\text { specific areas }\end{array}$ & $\begin{array}{l}\text { Regular reporting from } \\
\text { police or equivalent }\end{array}$ & $\begin{array}{l}\text { Police Department } \\
\text { of Heraklion/Traffic } \\
\text { Police, Municipal } \\
\text { Police }\end{array}$ & $\begin{array}{l}\text { Own } \\
\text { resources }\end{array}$ \\
\hline $\begin{array}{l}\text { Carbon emissions } \\
\text { of traffic in the city }\end{array}$ & $\begin{array}{l}\text { Outcome } \\
\text { Core } \\
\text { Environmental } \\
\end{array}$ & $\begin{array}{l}\mathrm{CO}_{2} \text { emissions of motorized } \\
\text { traffic }\end{array}$ & City wide & $\begin{array}{l}\text { Calculations based on } \\
\text { vehicle km and } \\
\text { emission factor, } \\
\text { existing data from } \\
\text { projects (RERUM) }\end{array}$ & $\begin{array}{l}\text { Municipality of } \\
\text { Heraklion } \\
\text { (Technical service), } \\
\text { University } \\
\text { Institutions }\end{array}$ & $\begin{array}{l}\text { Own } \\
\text { resources, } \\
\text { European } \\
\text { Projects }\end{array}$ \\
\hline $\begin{array}{l}\text { Clean Vehicles } \\
\text { Share }\end{array}$ & $\underline{\text { Contextual }}$ & $\begin{array}{l}\text { Percentage of clean vehicles } \\
\text { in total fleet }\end{array}$ & City wide & $\begin{array}{l}\text { Reports from } \\
\text { competent authorities }\end{array}$ & $\begin{array}{l}\text { Municipality of } \\
\text { Heraklion, Region } \\
\text { of Crete }\end{array}$ & $\begin{array}{l}\text { Own } \\
\text { resources }\end{array}$ \\
\hline
\end{tabular}

As stated before, monitoring and evaluation of smart mobility actions and measures is a fundamental part of Smart Mobility in general. When a set of policy measures and actions is implemented, it is considered mandatory to examine the impacts, the benefits and the possible deficiencies it has. Therefore, this task requires a monitoring process to be carried out. Monitoring constitutes an ongoing process which gives feedback and draws attention to crucial issues. Furthermore, monitoring contributes to the classification of these crucial issues, prioritizing the most urgent to be dealt with. This specific process should be adopted and run by local authorities and not by external partners, in order to enhance their role and strengthen their independence in both assessment and problem solving. Possible cooperation in the early stages of the monitoring procedure is still beneficial, only if emphasis is placed on transferring the potential know-how to the municipalities. Local authorities ought to be adaptable in such a new scientific perspective and they have to utilize proper strategies and tools to solve independently the occurring traffic and transportation problems.

A basic tool for monitoring the municipality's efficiency level is the creation of a City Dashboard. City Dashboards are portals which represent Data and Information about several elements of a city often at real- time. The main features of a Dashboard are: a) Legibility and Readability, b) open-access of the data, 
c) capability of combining different datasets, d) Innovative interface, e) Availability of different languages and f) Installation of City Dashboards in certain sites in the city. Certainly, Dashboards are one of the possible tools and strategies for monitoring. Heraklion has already a digital platform (https://smartcity.heraklion.gr/en/home/) which includes several features about the city such as weather condition, economical and demographical data etc. However, it is necessary to enrich these features, by adding public transport timetables and real-time traffic data as well as some of the aforementioned urban and transport indicators, thus improving the Smart mobility monitoring level of the city. Moreover, Heraklion city should not be limited solely to the Dashboard portal. Therefore, the introduction and adaptation of more functional tools will enlighten the way of the future aiming at efficiency, sustainability and economical effectiveness.

\section{CONCLUSION}

Sustainable urban mobility is fundamental to European and Mediterranean cities' social life and economy. In this context, SUMPs constitute a considerable opportunity for the cities' future, contributing to the enhancement and promotion of sustainable means and ways of transport in urban areas. Pleasant and affordable daily commuting, as suggested in SUMPs, is a key contribution to the quality of everyday life for citizens and can ensure accessibility, equity and increase of social cohesion. Smart solutions in the field of urban mobility aim to address these issues, while engaging citizens in action and removing obstacles in their communication. Smart mobility is an integral element of SUMPs, and Sustainable mobility in general, which requires a variety of infrastructure types, including physical infrastructure, operational and information technologies. Without any single part of this system, smart mobility cannot achieve an adequate efficiency level. On the one hand this paper has highlighted the significance of smart mobility as a principal element of Smart Cities and on the other the fundamentals of this importance; it has proposed a Smart Mobility Strategy along with its evaluation process for the city of Heraklion, which can be transferred to cities with similar characteristics and dynamics or needs. A set of categorized actions and indicators was presented, composing a plan which not only suggests new ways towards sustainable and efficient mobility, but also points out a monitoring procedure. Studying the experience of Heraklion in terms of its technological advances, its alignment to smart solutions in administrative level and the implementation of urban mobility projects has led to the conclusions that smart mobility parameters have to be studied and applied in accordance to the city's particularities and deficiencies.

The presented methodology, as applied through the case of Heraklion City, develops a creative toolbox with actions that can lead to smart paradigms of shifts in a daily commuting base as well as in the overall transportation culture of car-oriented cities. Moreover, the various indicators will contribute to examination and perhaps reconsideration of the suggested actions, contributing to the making of a more efficient Smart Mobility Plan. The crucial element in the suggested study remains the applicability and its potential outcomes in the future modal share. Critical issues raised from the above may also include the adaptability of local authorities in such a new scientific perspective along with their eagerness to adopt strategies and tools to solve long-established traffic and transportation problems.

Finally, the discussed issues within the overall concept of the smart city are expected to raise several research questions related to the role of mobility in cities, travel and mobility behavior, approaches in different age groups and different mobility attitude groups, as well as provide crucial outcomes in future transportation studies. This paper, as part of a series of ongoing research material, highlights the foundations of Smart Mobility Strategy and the way it is integrated to Sustainable Urban Mobility Plans, including both innovative and traditional policies and actions. Future interest in the field is addressing also actions for inclusion of various social groups, information and awareness as well as public engagement which shall allow for further exploration of innovative actions that involve the crowd in both problem solving and decision making. 


\section{REFERENCES}

Aleta, N. et al., 2017. Smart Mobility and Smart Environment in the Spanish cities. In Transport Research Procedia, Vol. 24, pp. 163-170.

Ambrosino, G. et al., 2015. A method to assess and plan applications of ITS technology in public transport services with reference to some possible case studies. In Case Studies on Transport Policy, Vol. 3, No. 4, pp. 421-430.

Bakogiannis, E., 2017. Using Traditional and New Digital Technology Tools to Promote Sustainable Mobility: Current Trends in the Evolving Transformation of the Smart City. In Stratigea, A. et al. eds Smart Cities in the Mediterranean: Coping with Sustainability Objectives in Small and Medium-sized Cities and Island Communities. Springer, Cham, Switzerland, pp. 113-133

Bencardino, M. and Greco, I., 2014. Smart communities. Social innovation at the service of the smart cities. In TeMA: Journal of Land Use, Mobility and Environment, pp. 39-51.

Benevolo, C. et al., 2016. Smart Mobility in Smart City. In Torre T. et al. eds Empowering Organizations. Springer, Cham, Switzerland, pp. 13-28.

Caragliu, A., et al., 2009. Smart cities in Europe. Proceedings of 3rd Central European Conference in Regional Science (CERS). Bratislava, Slovakia, pp. 45-59.

CEC, 2001. European transport policy for 2010: time to decide (White paper). Brussels, Belgium

CEC, 2007. Towards a new culture for urban mobility (Green paper). Brussels, Belgium

CEC, 2011. Roadmap to a Single European Transport Area: Towards a Competitive and Resource Efficient Transport System (White paper). Publications Office of the European Communities, Luxemburg

Dameri, R. P., 2017. Smart City Implementation. Progress in IS. Springer, Cham, Switzerland

Garau, C. et al., 2016. Cagliari and smart urban mobility: Analysis and comparison. In Cities, Vol. 56, pp. 35-46.

Giffinger, R. et al., 2007. Smart cities: Ranking of European medium-sized cities. Centre of Regional Science, Vienna UT, Vienna

Hojer M. and Wangel J. 2015. Smart Sustainable Cities: Definition and Challenges. In Hilty, L. and Aebischer, B. eds ICT Innovations for Sustainability. Springer, Cham, Switzerland, pp. 333-350.

Jabareen, Y., 2006 Sustainable urban forms: their typologies, models, and concepts. In Journal of Planning Education and Research, Vol. 26, No. 1, pp. 38-52

Lawrence, F. et al., 2006. Promoting public health through smart growth: Building healthier communities through transportation and land use policies and practices. Smart Growth BC, Vancouver, Canada

Marshall, S., 2005. Streets \& Patterns. Spon Press, Abingdon, UK

Neirotti, P. et al., 2014. Current trends in smart city initiatives-some stylised facts. In Cities, Vol. 38, pp. 25-36

Papa, R., et al., 2017. The evolution of smart mobility strategies and behaviors to build the smart city. Proceedings of the 5th IEEE International Conference on Models and Technologies for Intelligent Transportation Systems (MT-ITS), Naples, Italy, pp. 409-414.

Pickett, S. et al., 2004. Resilient cities: meaning, models, and metaphor for integrating the ecological, socio-economic, and planning realms. In Landscape and Urban Planning, Vol. 69, pp. 369-384.

Pitsiava-Latinopoulou, M., 2012. Sustainable Mobility indicators in urban areas. In Prospectus of Greek Transportations Engineers, Vol. 182, pp. 13-17

Schafer, A. et al., 2009. Transportation in a climate-constrained world. Mit Press, Cambridge, Massachusetts

Schneider Electric, 2014. Urban Mobility in the Smart City Age.

Vanolo, A., 2014. Smartmentality: The Smart City as Disciplinary Strategy. In Urban Studies, Vol. 51, No. 5, pp. 883-898.

Wefering, F. et al., 2014. Guidelines. Developing and Implementing a Sustainable Urban Mobility Plan. European Commission, Brussels, Belgium 